\title{
Challenges for Teachers in Knowledge Society
}

\author{
Dr. Md. Mahmood Alam ${ }^{1 *}$
}

\section{ABSTRACT}

Education is going through new transformations and, therefore, it will have to evolve in the direction of new globalizing knowledge society. The attempt to create the knowledge based society starts off successfully by bringing together the entire set of present day values that must prove the capacity of recreating the attitudes and practices of a global society. The perspective of knowledge summons and aligns the efforts towards: (i) Producing new knowledge through research activity (ii) Transferring knowledge through education and professional training (iii) Disseminating the knowledge by publishing and (iv) Utilizing knowledge in the society's best interest, especially through innovation. The need to find out new teaching methods and approach to learning arises from a complex range of factors - among them, changes in society and the economy; the potential for new forms of communication using emerging technologies; and rising expectations amongst learners that education will maximize their potential for personal fulfillment etc. In the 21st century, teachers need to be lifelong learners, adapting continuously to changed opportunities and demands of the knowledge economy. Therefore, the development of the knowledge based society minimizes the growing knowledge divide, reduce skill mismatches and promote a country's international competitiveness. If today's students want to compete in this global society, they must be proficient communicators, creators, critical thinkers, and collaborators (the "Four Cs"). This paper focuses on the characteristics, competencies and role of modern teachers for global world.

Keywords: Globalization, Knowledge Society, C’s, Competencies.

“Using the 'Four Cs' to engage students are imperative. As educators prepare students for this new global society, teaching the core content subjects-math, social studies, the arts- must be enhanced by incorporating critical thinking, communication, collaboration, and creativity. We need new tools to support classroom teachers and education support professionals in their profession, even as they implement new strategies in their classrooms” (John Stocks).

The knowledge society is a learning society in which information expands rapidly and circulates continuously around the globe. Economic success and a culture of continuous innovation depend

\footnotetext{
${ }^{1}$ Assistant Professor, MANUU College of Teacher Education, Sambhal (U.P.)

*Responding Author

(c) 2016 I M Alam; licensee IJIP. This is an Open Access Research distributed under the terms of the Creative Commons Attribution License (http://creativecommons.org/licenses/by/2.0), which permits unrestricted use, distribution, and reproduction in any Medium, provided the original work is properly cited.
} 


\section{Challenges for Teachers in Knowledge Society}

on the capacity of workers to keep learning themselves and from each other. Drucker puts it this way, "Knowledge workers will give the emerging knowledge society its character, its leadership and its profile". Teaching for the knowledge society involves developing deep cognitive learning, creativity, and ingenuity among students, pursuing continuous professional learning as teachers; and promoting problem-solving, risk-taking, trust in the collaborative process, ability to cope with change and commitment to continuous improvement. Teachers today therefore find themselves caught in a triangle of competing interests and imperatives

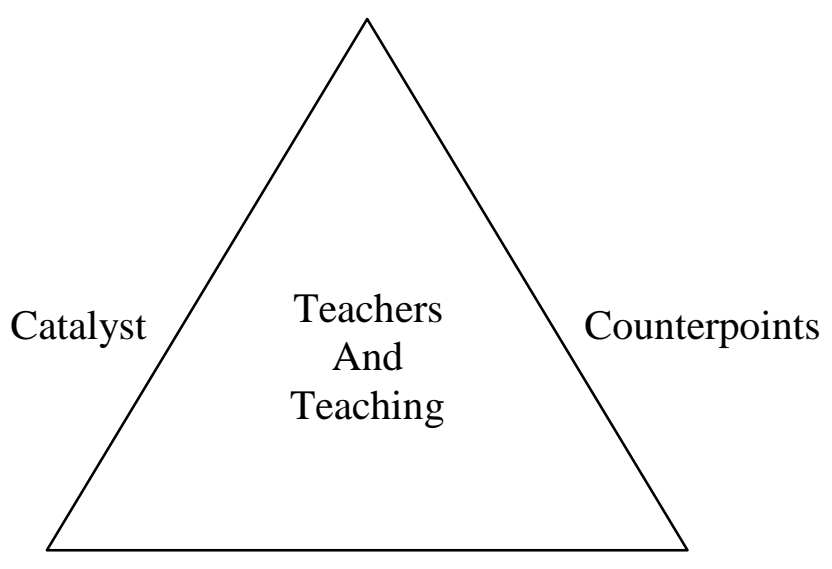

Casualties

- to be catalysts of the knowledge society and all the opportunity and prosperity it promises to bring;

- to be counterpoints for the knowledge society and its threats to inclusiveness, security and public life;

- to be casualties of the knowledge society in a world where escalating expectations for education are being met with standardized solutions, provided at minimum cost.

These three forces, their interactions and effects, are shaping the nature of teaching, what it means to be a teacher, and the very viability of teaching as a profession in the knowledge society. In general, as catalysts of successful knowledge societies, teachers must be able to build a special kind of professionalism. Teachers as catalysts of the knowledge society

- Promote deep cognitive learning

- Learn to teach in ways they were not taught

- Commit to continuous professional learning

- Work and learn in collegial teams

- Treat parents as partners in learning

- Develop and draw on collective intelligence

- Build a capacity for change and risk

- Foster trust in processes 


\section{Challenges for Teachers in Knowledge Society}

Teachers must therefore try to make their schools into learning organizations where capacities to learn and structures that support learning and respond constructively to change are widespread among children. In short, teaching for the knowledge economy fosters and thrives on: (a) creativity (b) flexibility (c) problem-solving (d) ingenuity (e) collective intelligence (f) professional trust (g) risk-taking and (h) continuous improvement. If teachers do not understand the knowledge society, they cannot prepare their students for it. From these generalities of context, to the specifics of our learners today, we need to create a new kind of school, with a new kind of professional teacher, which nurtures a new kind of learner. In every respect, the new teacher will take a greater degree of control of their professional lives and responsibility for their students' learning outcomes. To summarize:

\section{The New Learner:}

- is actively and purposefully engaged in their learning (the most effective learning is engaged learning);

- brings their experience, interests and voice to the learning task at hand;

- takes responsibility for their learning through a measure of autonomy and self-control;

- $\quad$ is a knowledge producer, drawing upon a range of available knowledge resources;

\section{Teacher as Designer}

- $\quad$ works effectively in collaborative knowledge activities and shares knowledge with peers;

- is comfortable in multimodal, digital knowledge-creation spaces;

- critically self-assesses and reflects upon their learning;

- engages in intensive collaborative learning;

\section{The New Teacher:}

- takes a greater degree of control of their professional lives, designing learning experiences for learners based on broad learning goals and curriculum standards;

- is a purposeful learning designer, rather than (just) a curriculum implementer;

- $\quad$ is comfortable working with learners in new, multimodal, online social media spaces;

- is a professional collaborator, contributing productively to a culture of professional support and sharing;

- differentiates instruction in order to cater effectively to learner diversity;

- is a leader in a dynamic, knowledge-producing community;

- is a practitioner-researcher, building and interpreting the evidence base of pedagogical inputs in relation to learner outcomes;

- creates and applies evaluation protocols to measure the effectiveness of pedagogies and programs.

Herein lies an enormous challenge, and an enormous opportunity for education. What education does - building the knowledge capital of a society, the creative capacities for innovation as well as the sensibilities to navigate ambiguity and complexity - is now fundamental. Traditional classrooms and bureaucratic education systems cannot provide society with what it now requires. 


\section{Challenges for Teachers in Knowledge Society}

The agenda of the new learning is to meet the needs of the knowledge society in a globalized world (Kalantzis \& Cope, 2008). If we commit to a vision of 21st century knowledge and skills for all students, it is critical that we support educators in mastering the competencies that ensure positive learning outcomes for students. These include:

- Successfully aligning technologies with content and pedagogy and developing the ability to creatively use technologies to meet specific learning needs,

- Aligning instruction with standards, particularly those standards that embody 21st century knowledge and skills,

- Balancing direct instruction strategically with project-oriented teaching methods,

- Applying child and adolescent development knowledge to educator preparation and education policy,

- Using a range of assessment strategies to evaluate student performance and differentiate instruction (including but not limited to formative, portfolio-based, curriculum-embedded and summative),

- Participating actively in learning communities; tapping the expertise within a school or school district through coaching, mentoring, knowledge-sharing, and team teaching,

- Acting as mentors and peer coaches with fellow educators,

- Using a range of strategies (such as formative assessments) to reach diverse students and to create environments that support differentiated teaching and learning.

\section{TEACHER COMPETENCES TO MEET THE CHALLENGES OF KNOWLEDGE SOCIETY}

The teacher must have some basic skills to be a good teacher. Firstly, he or she should have a profound knowledge of his/her subject area and have the skills to teach the students successfully. The following skills could be expected (according to Perrenoud, 1994):

- managing student learning progression;

- dealing with student heterogeneity;

- developing student commitment to working and learning;

- working in teams;

- participating in school curriculum and organization development;

- using new technologies in their daily practice;

- tackling professional duties and ethical dilemmas;

- managing their own professional development.

Since a teacher's knowledge and skills depend on his/her continuous learning and development, he/she should deal with current research and be aware of general social changes.

\section{CHANGING DIMENSIONS OF THE ROLE OF TEACHERS AND TRAINERS}

The following changes in competences formally required of teachers (and trainers). These changes were introduced in response to issues of student intake, teaching environment, and contextual factors including general social trends and developments in the labor market. 


\section{Challenges for Teachers in Knowledge Society}

(A) Impact of Social Changes

Promoting new learning outcomes

- Contributing to citizenship education of students/trainees such as

1. Living in a multicultural, inclusive and tolerant society;

2. Living according to sustainable lifestyles regarding environmental issues;

3. Dealing with gender equity issues in work and social life;

4. Managing his/her own career development; etc.

- Promoting the development of competences of students/trainees for the knowledge and lifelong learning society such as

1. Motivation to learn beyond compulsory education;

2. Learn how to learn/learning in an independent way;

3. Information processing;

4. Digital literacy;

5. Creativity and innovation;

6. Problem-solving;

7. Entrepreneurship;

8. Communication;

9. Visual culture; etc.

- Linking the development of new curriculum competencies with school subjects

(B) Diversity of student intake and changes in the teaching environment

1. Working in restructured ways in the classroom

$>$ Dealing with social and cultural diversity of students

$>$ Organizing learning environments and facilitating learning processes

$>$ Working in teams with teachers and other professionals involved in the learning process of the same students

2. Working "beyond the classroom": in the school/training centre and with social partners

$>$ Working in school curriculum, organizational development and evaluation

$>$ Collaborating with parents and other social partners

\section{Integrating ICT in formal learning situations and in all professional practice}

(C) Increasing levels of teaching professionalization

\section{Acting as professionals}

$>$ Acting in an investigative or problem-solving way

$>$ Assuming greater responsibility for their own professional development in a lifelong learning perspective.

Thus 21st century learning frameworks may be depicted as below: 


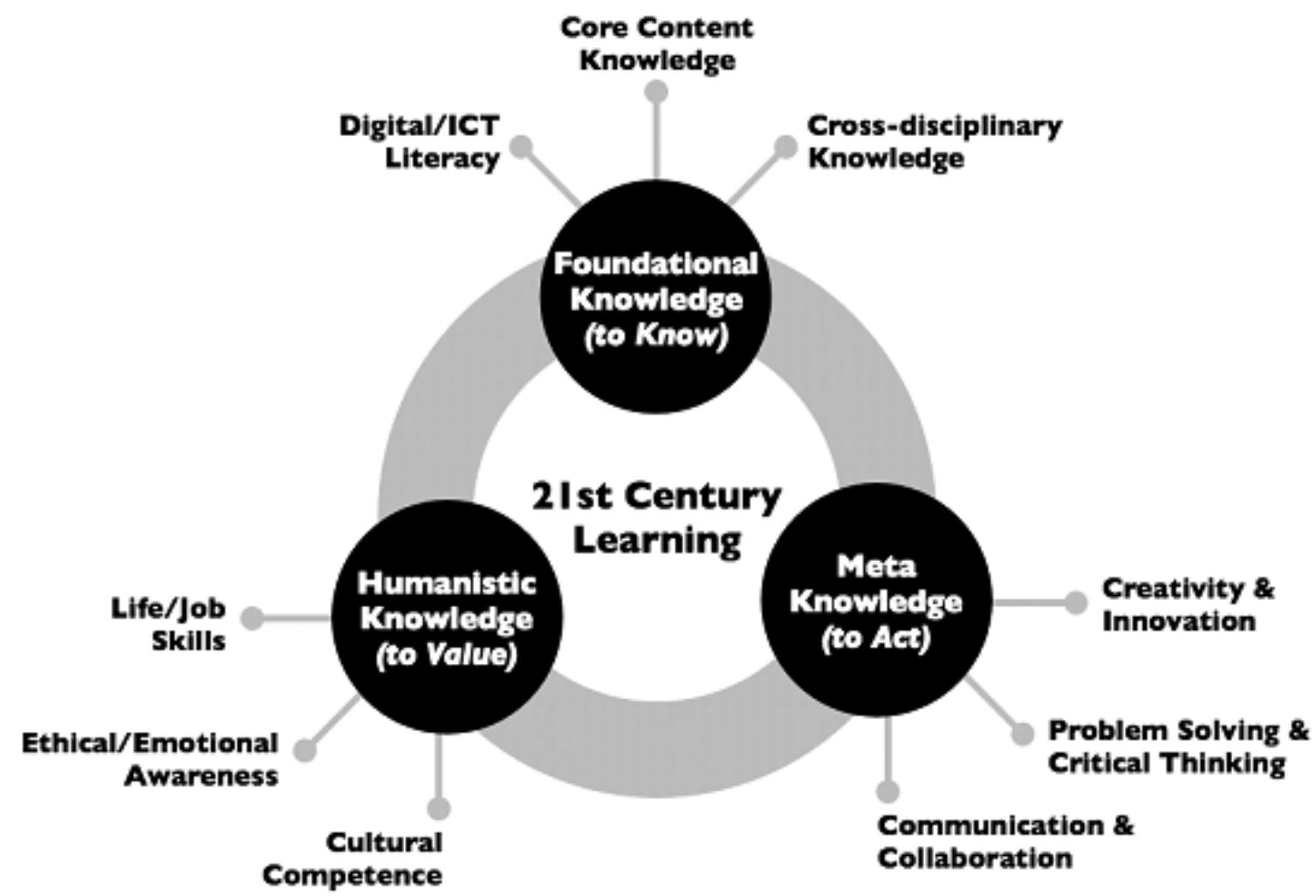

\section{RECOMMENDATIONS}

Successful learning at school is the foundation of lifelong learning by individuals and the globalised, knowledge society of the future. The continued creation, dissemination and utilization of knowledge in all spheres of human activity, together with a sound, ethical base and moral values, is the pathway to a successful life for all people. Teachers have to come to terms with ever rising expectations and constantly changing societal requirements. While effective student learning remains the dominant, constant criterion of successful teaching, the nature of what is to be learnt, the best ways of learning and the needs of students are constantly evolving. It is of vital importance that the talents of teachers are given full expression to enable teachers to achieve the learning outcomes that students and the community need. The emphasis needs to shift toward quality of experience and quality of performance - in teacher education, induction, professional development, career planning and everyday life in the school. Directions for action arising from this study fall into four broad areas:

\section{A career of choice.}

Teacher policies need to become more targeted, making teaching a career of choice for talented people who are committed to attaining and demonstrating high quality teaching as a career goal. The elements of entry into teaching and professional conditions of service need to be closely linked to teachers' primary motivation and interests, a deep sense of a worthwhile occupation and autonomy and salary and institutional conditions. More investment in recognition of performance by teachers and the quality of their work by human resources managers is needed, in order to enhance teacher satisfaction, achieve a better quality of service and improve retention rates. 


\section{Challenges for Teachers in Knowledge Society}

\section{Reducing attrition.}

While career mobility has many benefits, attrition of able student teachers who demonstrate good teaching potential and of capable early career teachers merits attention. Attrition rates could be reduced through more personal career guidance in training, more comprehensive and supportive induction and systematic career mapping and counseling within the early years of teaching.

\section{Mature age entrants with career experience in other occupations.}

Selection, training, recruitment, allocation of duties and professional development all need to pay close attention to the specific expertise, experience, expectations and attitudes that career change entrants bring to teaching rather than to assume that they are broadly similar across all entrants to the profession. The experience of career change entrants needs to be better acknowledged within teaching since, as professionals, they are by no means beginners.

\section{Leadership responsibilities in schools.}

Teachers in their initial years in the profession express very positive attitudes toward responsible, caring positional leadership. Those in positional authority in schools should be encouraged to play a greater role in formation and development of teachers both in training and in the early years of their careers.

\section{The demands of a knowledge-based society and economy.}

New Innovations in curriculum, assessment, pedagogy, changing social contexts and economic trends need teachers o have socially and economically relevant foundations of professional knowledge, and be encouraged to articulate and communicate that knowledge in diverse educational settings.

6. Meeting the social and emotional as well as the intellectual and vocational needs of children.

Through their initial preparation as teachers and their continuing professional development, and in their daily work, teachers need to give attention to the social and emotional dimensions of education than to the intellectual and vocational.

\section{The image of education, the status of teaching.}

Teaching and the value of education need to be talked up - by teachers and trainee teachers to their students. Educational scholars, researchers and policy makers need to draw out and publicize the absolute dependence of the knowledge society and economy and of an innovative culture on high quality schooling and therefore teaching.

\section{Flexible use of time.}

Teachers should have degree of flexibility in the use of time to accommodate a more favorable work/ life balance. Schools should be encouraged to become more creative and innovative in the way the school day/ week/ year is organized and in defining the roles and responsibilities of professionals working in them. Learning and teaching should shape structure and roles, not vice-versa.

\section{Selection of teacher education students.}

Selection for teacher education should be more definitely focused on aptitude for a teaching career, balancing academic attainment with ability to communicate, to work effectively with others, and to exercise social responsibility. 


\section{Challenges for Teachers in Knowledge Society}

\section{Review and accreditation.}

Judgments about professional standard need to be taken more seriously as part of the course review and accreditation process and there should be more active collaboration among the various stakeholders in the design, implementation and review of teacher education programmes.

\section{The theory component of initial teacher education.}

There should be a regular periodic review focused on how the academic components of teacher education can more effectively interrelate with the professional requirements of teaching.

\section{Recognizing performance.}

Procedures for recognizing and rewarding high quality performance should be introduced within the profession.

\section{Career mapping.}

Career mapping and systematic career advice should feature in teacher education For all teachers regardless of career intent, initial induction, career counseling and professional development opportunities should be not only available, but used more systematically. Procedures are needed at both system and school level for linking evaluation of performance and career planning.

\section{The conditionality of teaching.}

Following initial career guidance and mapping opportunities, employment options and requirements should include a more individualized focus on professional learning opportunities which enhance teachers' career development and the quality of their teaching, and on high quality school environments. Administrative requirements or demands that adversely affect teaching time - requirements or demands that reduce the quantity and quality of teaching time should be minimized.

\section{Continued professional learning.}

More collaboration and concerted efforts are needed among stake holders in order to further raise professional standards, address specific weaknesses, and improve the image and status of teachers.

\section{CONCLUSION}

There is a crack in everything.

That's how the light gets in.

(Leonard Cohen, Anthem, Leonard Cohen Stranger Music, 1992)

Education is the single most important path to development and the basis of the future society. It requires expanding the vision of what it means to prepare educators for their future roles. In response to these demands of the knowledge society and the teaching profession, teachers need to be prepared suitably. The paradigm suggested for this is based on the dimensions that call for teacher educators to facilitate engaged learning with scope for autonomy, problem solving and collaboration especially through ICTs. When learning is characterized by inquiring, questioning, thinking, organizing and articulating then students require the capacities and space to explore, 


\section{Challenges for Teachers in Knowledge Society}

challenge, analyze, critique and create. Students and teachers alike learn their way around living landscapes of knowing. Along with this change in how we understand learning and curriculum, a whole array of related educational initiatives will need reconsideration: (i) Assessment (ii) Resources (iii) Professional Development (iv) Teacher Education (v) School and District Leadership and (vi) Education Policy. Curricula for the 21st century have to be designed to address what we now understand about learning and the ways in which learning and teaching, learners and teachers, are always housed within living landscapes of knowledge. Thus "We must prepare young people for living in a world of powerful images, words and sounds" (UNESCO, 1982).

\section{REFERENCES}

American Association of Colleges for Teacher Education (2008), "Handbook of Technological Pedagogical Content Knowledge for Educators (TPCK)”, New York: Rout ledge.

Drucker, P. F. (1994), "Knowledge Work and Knowledge Society”, The Social Transformations of this Century Edw in L. Godkin Lecture at Harvard University, John F. Kennedy School of Government.

Hargreaves, A. (2003), "Teaching in the Knowledge Society: Education in the Age of Insecurity”, Teachers College Press, 1234 Amsterdam Avenue, New York, NY.

John Stocks, "Preparing 21st Century Students for a Global Society, An Educator's Guide to the "Four Cs".

Kalantzis, M. and Cope, B. (2008), "New Learning: elements of a science of education", Cambridge: Cambridge University Press.

Kristen, K. et al. (2013), "What Knowledge Is of Most Worth: Teacher Knowledge for 21st Century Learning”, Journal of Digital Learning in Teacher Education, Vol. 29, No 4.

Malcolm, S. and Helen, C. (2004), "Teachers for the Future - The Changing Nature of Society and Related Issues for the Teaching Workforce", DEST, Canberra. Victoria.

Mary, K. and Bill, C. (2010), "The Teacher as Designer: pedagogy in the new media age”, Journal of E-Learning and Digital Media, College of Education, Vol. 7, No. 3, University of Illinois, Urbana-Champaign, USA.

Perrenoud, P. (1994), “Compétences, habitus et savoirs professionnels”, European Journal of Teacher Education, Vol.17, No. 1-2,pp. 45-48.

Sharon P. et al. (2010), "21st Century Knowledge and Skills in Educator Preparation”, Valerie Greenhill Ken Kay Alyson Nielson.

Yasemin, D. and İbrahim, K. (2013), "Educating Teachers for the Global World”, International Journal of Humanities and Social Science, Vol. 3, No. 19. 